\title{
STRUCTURAL PERFORMANCE AND DURABILITY ISSUES OF VERNACULAR SCHIST MASONRY
}

\author{
CARLOS E. BARROSO ${ }^{1 *}$, DANIEL V. OLIVEIRA ${ }^{2}$ AND LUÍS F. RAMOS ${ }^{2}$ \\ ${ }^{1}$ Center for Studies in Architecture and Urbanism (CEAU) \\ University of Porto, Faculty of Architecture (FAUP) \\ Via Panorâmica s/n, 4150-564 Porto, Portugal \\ e-mail: cbarroso@arq.up.pt, www.ceau.arq.up.pt (*corresponding author) \\ ${ }^{2}$ Institute for Sustainability and Innovation in Structural Engineering \& \\ Institute of Science and Innovation for Bio-Sustainability (ISISE \& IB-S) \\ University of Minho, School of Engineering \\ Campus de Azurém, 4804-533 Guimarães, Portugal \\ email: danvco@civil.uminho.pt, lramos@civil.uminho.pt,www.isise.net
}

Keywords: Vernacular Masonry, Schist, Axial Compression, Retrofitting, Durability

\begin{abstract}
Stone masonry is recognized as one of the most used vernacular construction techniques around the world. Although centuries of proven resilience and high adaptability to context, stone masonry has been progressively replaced in construction industry in the last decades, namely in countries as Portugal, by industrial and concrete-based materials and building systems. Nowadays, with the lack of traditional masons, an important part of traditional stone masonry constructive know-how is endangered. In face of growing concerns regarding heritage preservation, researchers are aware of the need to scientifically know such structures. Being less studied, vernacular schist rubble masonry was selected as case study and tested to characterize its mechanical behaviour and durability parameters. The potential of retrofitting of such structures was also assessed [1].

Eighteen double-leave wallets were built following local building traditions [2] and prepared according to 3 different setups of 6 specimens each: $i$ ) non-coated; ii) coated with commercial lime coating; iii) coated with commercial lime coating and injected with lime-based grout. The experimental campaign was designed and implemented in stages for a period of three years: i) experimental characterization of stones and mortars; ii) axial compression testing of reference specimens; iii) salt-based accelerated aging following wet-dry procedures [3]; iv) axial compression testing. Damage progression was monitored by visual inspection, mass variation and sonic testing [4].
\end{abstract}

\section{INTRODUCTION}

Stone masonry has been for centuries a main tool used all around the world, helping mankind to shape its territory, and thus answer community's survival needs. Built using almost all kind of available natural materials, a wide diversity of types of masonry can be found, being most examples developed for specific uses. In Western Europe, the long stone masonry building tradition lost its leading role around the mid-20th century due to strong industrialization of 
construction, mostly based on cement products. As a result, much of the empirical knowledge associated to vernacular stone masonry is endangered. Such risk is much higher in rural contexts, due to the loss of traditional ways of life, but also due to rural abandonment that leaves stone masonry structures without any kind of maintenance. Resulting from centuries of trial error experience-based knowledge, stone vernacular masonry heritage has been used as active farming and territory management tools until recent decades [5]. Such heritage is a vital element of the rural landscape and part of its priceless cultural value due to its high authenticity (tangible value) $[6,7]$. For being a testimony of past ways of life, vernacular stone masonry is an inseparable dimension of European rural identity (intangible value) [8]. However, vernacular masonry preservation faces severe challenges, mostly related with insufficient knowledge. Although academia's recent investment, scientific and technical knowledge on the topic of preserving vernacular heritage is still scarce.

Taking into consideration the risks, but also the social-economic potential of such endeavour, a research was undertaken to understand the structural behaviour of vernacular masonry. Aligned with ongoing research on the topic [2], Northwestern Portuguese vernacular schist rubble stone masonry was selected as case study for this paper.

\section{METHODOLOGY}

To achieve the research objectives, schist rubble masonry was tested for axial compression to determine its main mechanical parameters. Also, to understand the influence of durability over masonry structunal perfonmance, axial compression tests were performed on acceleratedaged masonry. The topic of masonry preservation was also masonry under both test

Eighteen schist rubb laboratory environment (W) were prepared according to specific setups ar
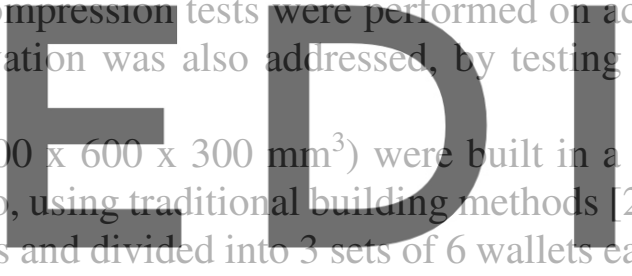
retrofitted
controlled
2]. Wayets
ach,being: i) non-coated masonry $(\mathrm{N})$; ii ) coated masonry using commercial lime mortar similar to

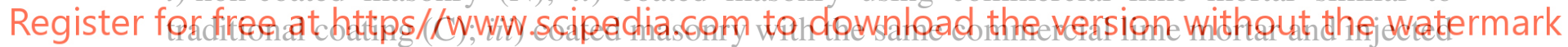
with a lime-based grout (I). Wallets were then tested under two different test conditions (3 wallets of each set and test condition) to obtain reference and durability mechanical parameters, namely wallets tested after the curing period (WU) and wallets tested after being aged (WA).

The experimental campaign was designed and carried out in three different stages (three years period) as follows: $i$ ) wallets were built and left to cure for a period of 120 days; $i$ ) WU wallets were tested under axial compression; iii) WA wallets were aged using a specifically designed saltbased accelerated aging test, divided into a salt loading stage of 9 wet-dry cycles during 2 months, followed by an aging stage at natural conditions, for 12 months; $i v$ ) WA wallets were tested under axial compression. During this time period, complementary tests were performed to collect additional data (results under elaboration), namely: $i$ ) main physical and mechanical parameters of stones and mortars [9]; ii) sonic testing of walls at the beginning and throughout the accelerated aging period to assess the potential of applying such technique to determine rubble masonry parameters [4]; iii) regular visual inspection of walls and mass variation analysis. 


\subsection{Wallets construction}

Wallets were built by a professional stonemason using local schist stone blocks (average compressive strength $f_{\mathrm{c}}$ of $35 \mathrm{MPa}$ on both anisotropic directions), collected from demolished buildings, being their final shape given on-site. Local granitic soil, locally named "saibro", was used as bedding and joint mortar. Soil was sifted and mixed with water until reaching the required workability (between $160 \mathrm{~mm}$ and $180 \mathrm{~mm}$ checked by flow table test), resulting in a very poor mortar $\left(f_{\mathrm{c}}<0.1 \mathrm{MPa}\right)$, known for regaining workability if wet. As shown in Figure 1 , double-leaf cross-sections (30 cm wide) were built by overlapping header and stretcher proportioned parallelepiped stone blocks of different sizes $(<250 \mathrm{~mm} \mathrm{x}<60 \mathrm{~mm} \mathrm{x}<400 \mathrm{~mm})$. Stones were bedded parallel to foliation orientation, using small size schist wedges and soil mortar. Wallets' wythes were connected by using bond stones and by overlapping stone blocks at the inner core. The inner core was filled with soil mortar and small stones. Joints were pointed with soil mortar.
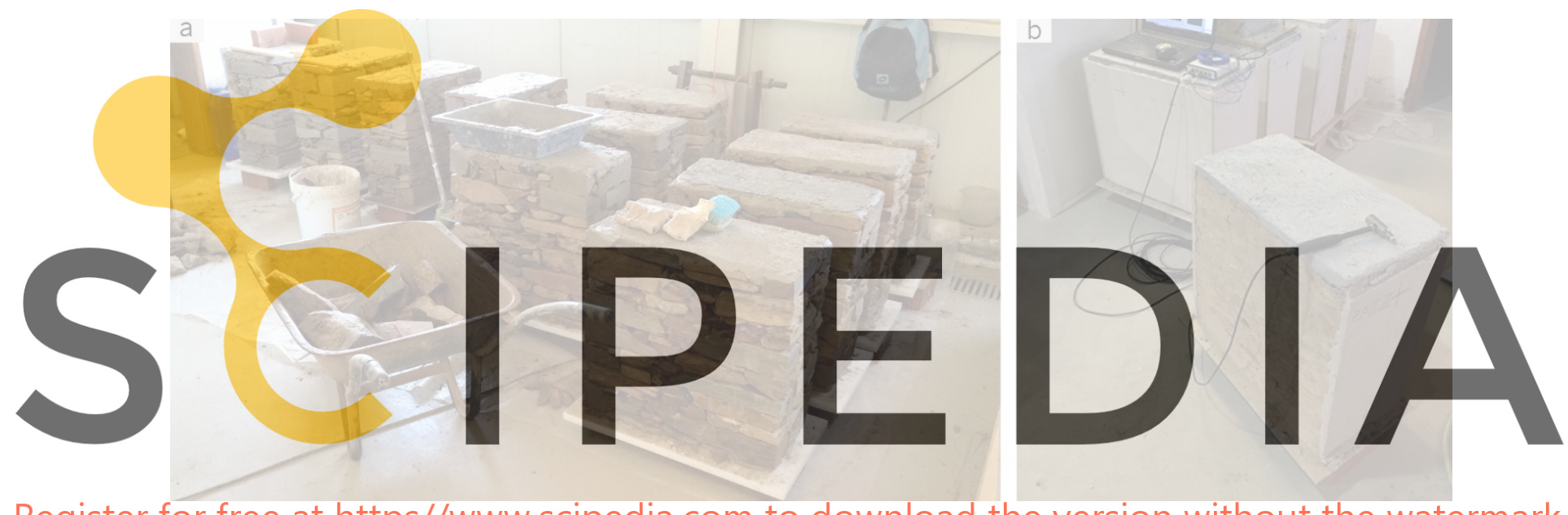

Register for free at https//www.scipedia.com to download the version without the watermark Figure 1: Wallets: (a) construction stage; (b) sonic testing.

As illustrated in Figure 2, wallets were built over either a $50 \mathrm{~mm}$ thick iron plate (WU) or a $300 \mathrm{~mm}$ thick nylon plate (WA). The latter was selected for its resistance to salt damage. As shown in Figure 3a and Figure 3b, cross-section was built over a $20 \mathrm{~mm}$ layer of cement mortar.

At the top, a cap of cement mortar was also built to stabilize the masonry. Afterwards, see Figure $3 \mathrm{c}$, the main faces of wallets were coated with a commercial lime mortar exhibiting a performance similar to traditional lime mortars, and it was applied in two layers with an average thickness of $20 \mathrm{~mm}$. Lateral faces were coated with a another lime-based mortar with $15 \mathrm{~mm}$ thick, reinforced with a commercial acrylic mesh. The purpose of the later was to improve walls resistance during transport and water immersion operations. To allow transporting and injecting wallets, a second $50 \mathrm{~mm}$ thick iron plate was placed over the cap, with styrofoam absorber in between, and attached with rods to the base plate.

Grout injection was applied to I wallets after repointing the joints with soil and before applying the coatings (see Figure 3d). Injection hoses were inserted into the masonry fabric forming a grid 
pattern. Water was injected to moisten the masonry. After a period of $24 \mathrm{~h}$, a commercial limebased grout was injected at low pressure from the bottom towards the top of the wall.

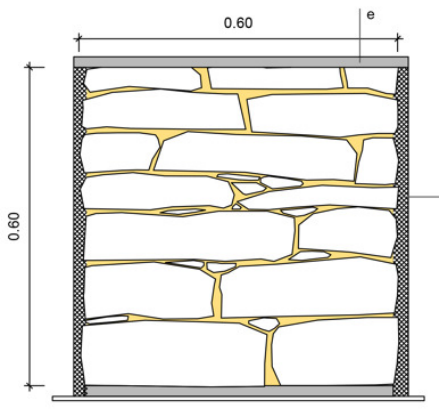

FRONT ELEVATION - WUA

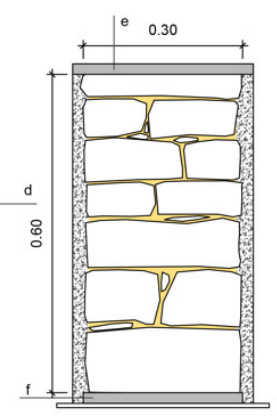

VERTICAL SECTION - WUC

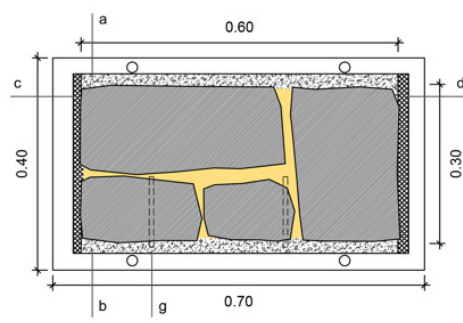

HORIZONTAL SECTION - WU

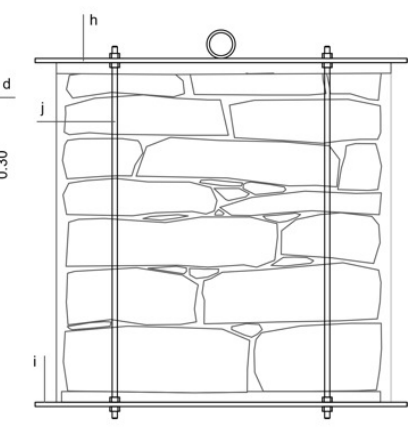

SETUP TO MOVE THE WALLETS

Figure 2: Schist masonry wallets schematics (dimensions in meters): (a) and (b) main faces coated with commercial lime mortar similar to traditional mortar; (c) and (d) lateral covers coated with commercial lime mortar; (e) top cement cover (stabilizing layer + levelling layer); (f) cement base layer; (g) grout injection hoses; (h) top transport and injection iron plate; (i) base plate in iron (WU) or Nylon (WA); (j) iron rods.
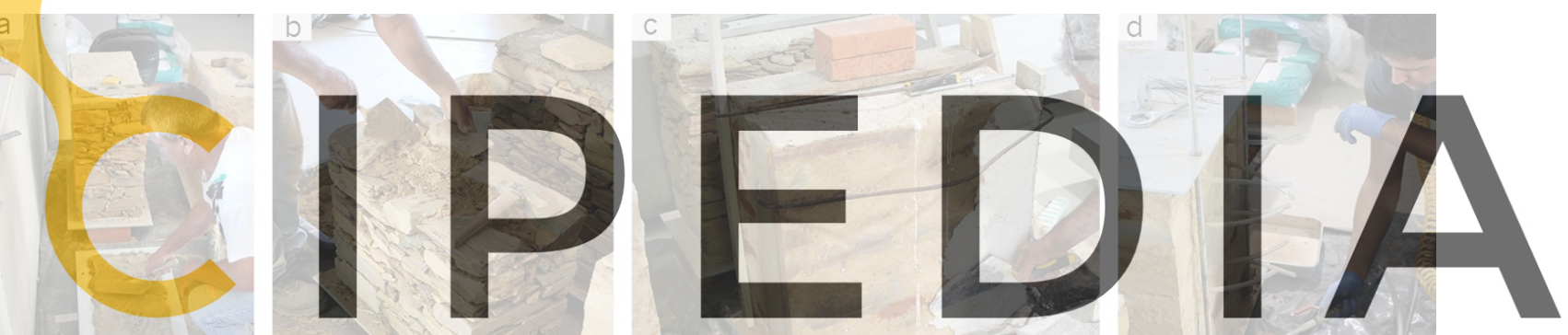

Register for free at https//www.scipedia.com to download the version without the watermark

Figure 3: Wallets construction stages: (a) bottom cement mortar layer; (b) construction procedure; (c) application of the main faces coating; (d) grout injection.

\subsection{Compression tests}

Axial compression tests were performed to determine masonry wallets strength $\left(f_{\mathrm{c}}\right)$ and elastic parameters $(E)$ [10], using a servo-controlled actuator under axial displacement control at a rate of $20 \mu \mathrm{m} / \mathrm{s}$. As shown in Figure 4, LVDTs were used to monitor displacements between plates (P1-P2), and to monitor deformations on the walls faces (main faces: V1-V2; H1-H2; lateral faces: H3-H4). Preliminary testing showed that due to schist well-defined foliation, thus with high risks of lamellar disaggregation, the use of bolts to attach LVDTs to masonry was unfeasible. Therefore, glue was used to attach LVDTs. All coatings were prepared in order to avoid its direct contact with the loading plates, so the axial load was applied to the masonry wall only. 
Observations during the WU compression tests showed an early detachment of the coatings, making the attached LVDTs data unusable. Moreover, attaching LVDTs to WA wallets was unfeasible due to salt presence. Therefore, the setup was adjusted for the second stage of compression tests, reducing the number of LVDTs to the P1-P2 (see Figure 4c). If required, the top of wallets was levelled with a very thin layer of fast hardening mortar. A spherical seat was used under the top loading plate to ensure specimens a proper alignment and adjustment to the loading plates. For each set, a first wallet was tested under axial monotonic compression to determine the peak load. Based in this value, parameters for the cyclic tests were set: $i$ ) until peak load, unloading procedure was controlled by load, and started at every $30 \mathrm{kN}$ of additional load for $\mathrm{N}$ and $\mathrm{C}$ wallets, and $150 \mathrm{kN}$ for I wallets; $i$ ) after peak load, unloading was controlled by displacement, and started at every $12 \mathrm{~mm}$ for $\mathrm{N}$ and $\mathrm{C}$ wallets, and $20 \mathrm{~mm}$ for I wallets; iii) reloading was started when unloading force reached $10 \mathrm{kN}$.
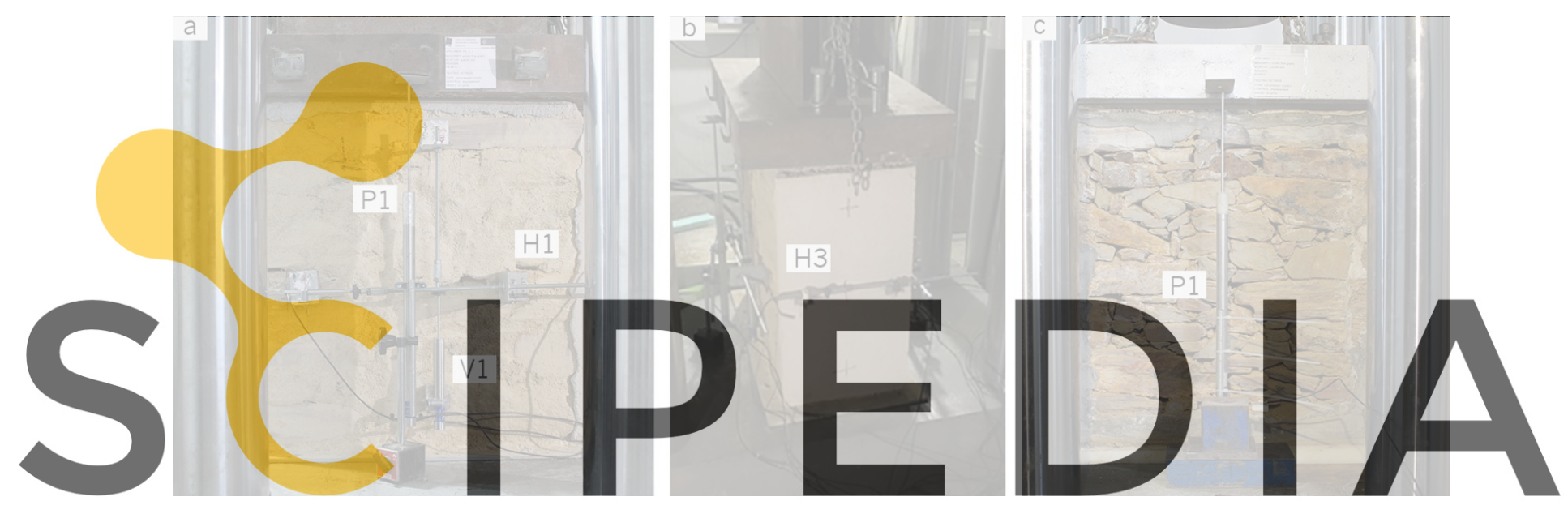

Figure 4: Axial compression test setup; (a, b) WU wallets; (c) WA wallets.
Register for free at https//WwW.scipedia.com to download the version without the watermark

\subsection{Accelerated aging tests}

For its known damaging effects over masonry, salt was selected as weathering agent $[11,12]$. Masonry wallets were subjected to wet-dry cycles with full immersion into a $20 \%$ sodium chloride $(\mathrm{NaCl})$ solution by weight. The selection of the salt was carried out using preliminary salt weathering tests on cubic specimens [13]. Sodium sulphate decahydrate $\left(\mathrm{Na}_{2} \mathrm{So}_{4} \cdot 10 \mathrm{H}_{2} \mathrm{O}\right)$ was ruled out for its excessive destructive effect over schist, as shown elsewhere [9]. $\mathrm{NaCl}$ is a hygroscopic and deliquescence salt, meaning that it absorbs atmospheric moisture and can form a solution, if environmental $\mathrm{RH}$ is above salt's equilibrium $\mathrm{RH}$ at a given temperature $\left(30{ }^{\circ} \mathrm{C}, 75.1 \% \mathrm{RH}\right)$ $[12,14]$.

By varying temperature and RH conditions during the WA testing, the number of dissolutioncrystallization cycles increased, inducing a higher level of damage to wallets [3]. Taking into consideration the unfeasibility of oven-drying the wallets, a $20 \%$ concentration by weight was selected as suitable for such required effect. Wallets were previously weighted, and to ensure water absorption only through the main faces, a waterproofing coating was applied over the top and lateral covers, see Figure 5a. 
The WA test was implemented in two stages: $i$ ) an initial wet-dry cyclic stage to load wallets with salt (WA1), see Figure 5b; ii) a subsequent natural drying stage under laboratory conditions (WA2), see Figure 5c. WA1 was implemented into 9 cycles (168 hours of duration each), being each cycle started with an initial full immersion stage (72 hours), during which the solution was kept in continuous motion to avoid areas of salt crystallization (walls and edges of the tank), followed by a monitored and controlled drying period inside the enclosed tank (96 hours). In turn, each drying period was subdivided into a period of drying with heated ventilation (7 hours with an average of $40{ }^{\circ} \mathrm{C}$ and $25 \% \mathrm{RH}$ ), followed by natural drying ( 17 hours with an average of $23{ }^{\circ} \mathrm{C}$ and $78 \% \mathrm{RH})$. WA2 drying lasted for a continuous period of 365 days, in which wallets were kept at room temperature and RH, inside the opened tanks. Environmental conditions variations along this period where monitored but not controlled. To monitor damage progression, wallets were again weighted at the end of the test, and visually inspected, photographed and analysed with sonic testing at each cycle and test stage. To monitor the effectiveness of the salt solution, 5 cubic stone specimens were placed inside the tank. These were weighted, visually inspected and analysed by UPV at each cycle and test stage. The solution temperature was on average $25^{\circ} \mathrm{C}$, being samples collected to check concentration by weight variation. If needed, salt or water were added.
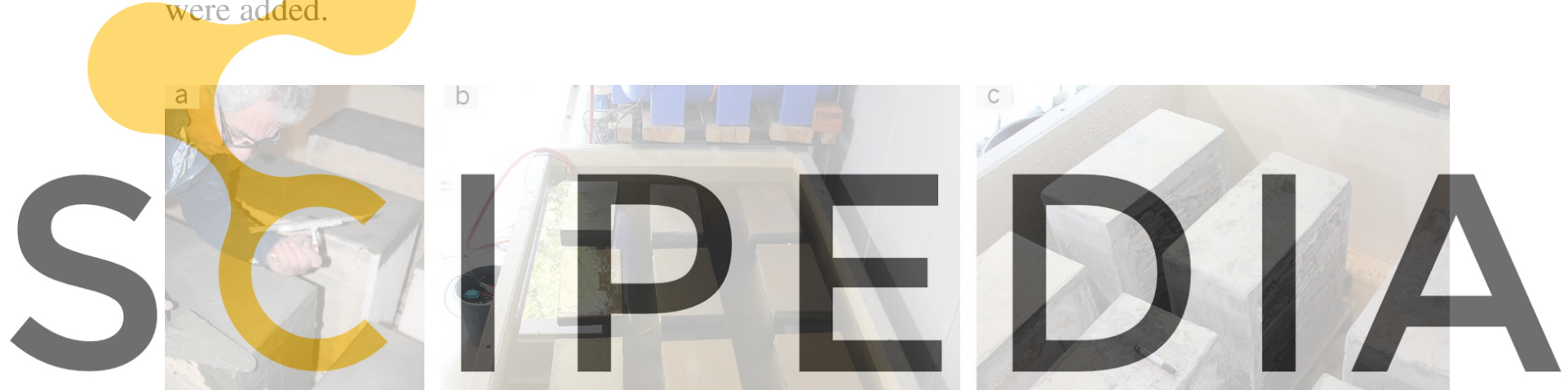

Figure 5: WA test: (a) application of the final waterproofing coating (b) filling of the tank with salt solution for immersion of wallets (WA1); (c) wallets during the natural drying stage (WA2).

\section{RESULTS}

WU test results are presented in Table 1, which reveal a lower compressive strength $\left(f_{\mathrm{c}}\right)$ in comparison with other common types of Portuguese stone masonry presented in Table 2. Non-injected $\mathrm{N}$ and $\mathrm{C}$ wallets were only stronger than adobe masonry. Analysing results for the elastic modulus $(E)$, both present low values. Analysing results for inject I wallets, average values for $f_{\mathrm{c}}$ are similar to the reference schists, although with a higher average value for $E$. These results demonstrate the positive effect of grout injection over rubble schist masonry strength and stiffness. A detailed analysis to $\mathrm{N}$ and $\mathrm{C}$ wallets mechanical parameters, show similar $f_{\mathrm{c}}$ values, thus revealing no significant influence of traditional coating over strength. However, and although higher values for CoVs and $E$ values for $\mathrm{C}$ wallets may indicate some influence of traditional coating over masonry elastic behaviour. The obtained results for strength and stiffness may be explained by schist stone initial weathering, taking into 
consideration the origin of the stones, the very low strength of its soil mortars, and the high percentage of voids of the tested rubble masonry. Using I wallets specific weight (average of $19.30 \mathrm{kN} / \mathrm{m}^{3}$ ) and the known volume of injected grout (27l on average), the masonry voids index was calculated revealing high average percentage of voids of about $24 \%$.

Analysing in detail results for I wallets, obtained values show an undeniable performance improvement, being 5 times stronger (on average) than non-injected walls, 2 times stiffer (on average) than $\mathrm{N}$ and 5.5 times (on average) than $\mathrm{C}$. The compressive strength increase of injected wallets in comparison with non-inject wallets is similar to the gain values obtained elsewhere [15] for compressive strength, but higher regarding $E$ gains (injected schist wallets tested in [15] were 3 times stronger and stiffer than non-injected ones).

Analysing Table 1 regarding WA wallets results, the loss of strength and stiffness is visible for all tested walls. Being on average 1.3 and 1.4 times weaker and on average 2 and 5 less stiff, results show non-injected wallets higher susceptibility to the WA test. On the other hand, being in average 1.1 times weaker and 1.4 times less stiff, injected I wallets showed higher resilience to the WA test. Explanation of such results may be related to the high percentage of internal voids of non-inject $\mathrm{N}$ and $\mathrm{C}$ wallets, which acted as moisture penetration and accumulation points, decisively contributing to the higher levels of observed damage. In the same way, lower losses of mechanical performance for I wallets may be pointed to the lower percentage of internal voids, thus being less exposed to water penetration and resulting in lower level of observed damage. Preliminary tests showed schists strong water absorption (average $A_{b}$ of $7.5 \%$, see [9]), thus higher susceptibility to salt damage [11,12]

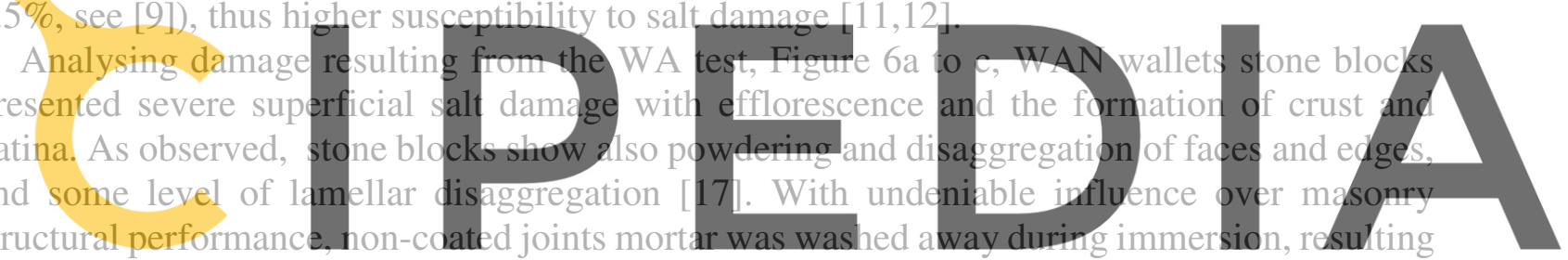
in cases of loose wedges. As observed, soil mortars settled at wallets lower half, changed the

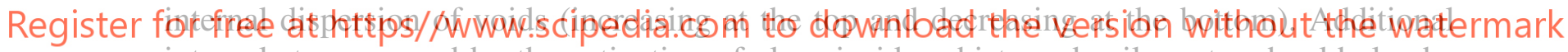
internal stress caused by the activation of clays inside schists and soil mortar should also be taken into consideration $[14,18]$.

Table 1: Strength $\left(f_{\mathrm{c}}\right)$ and elastic modulus $(E)$ results (in $\left.\mathrm{MPa}\right)$.

\begin{tabular}{ccccccccccccc}
\hline \multirow{2}{*}{$\begin{array}{c}\text { Test } \\
\text { conditions }\end{array}$} & \multicolumn{9}{c}{$\mathbf{N}$} & \multicolumn{1}{c}{$\mathbf{C}$} & \multicolumn{3}{c}{$\mathbf{C}$} \\
\hline
\end{tabular}

Note: Compression $\left(f_{\mathrm{c}}\right)$ and elastic modulus $(E)$ average results are indicated in bold; Standard deviation $(\mathrm{SD})$ is indicated inside rectangular brackets; Coefficient of variation $(\mathrm{CoV})$ is indicated in percentage inside rounded brackets. 
Water penetrated through the coating applied to $\mathrm{C}$ wallets main faces and accumulated inside, causing the same type of damage above-described. It is noteworthy that all coatings showed severe effloresce and salt accumulation, with WAC and WAI wallets main faces coating presenting areas of granular disaggregation. The loss of lime coating stiffness was confirmed during the sonic tests. As observed, such type of coating became successively less stiff after each wet-dry cycle, being this damage severe in the case of WAC wallets, due to the strong presence of internal moisture. The loss of performance of main faces coatings can explain the WAC strong drop in $E$ parameter. As shown in Figure 6d and f, internal stress combined with salts accumulation at the stone/coating interface led to lime coatings early detachment in WAC. Such damage was not detected in WAI wallets.

Table 2: Results from common types of Portuguese stone masonry [16].

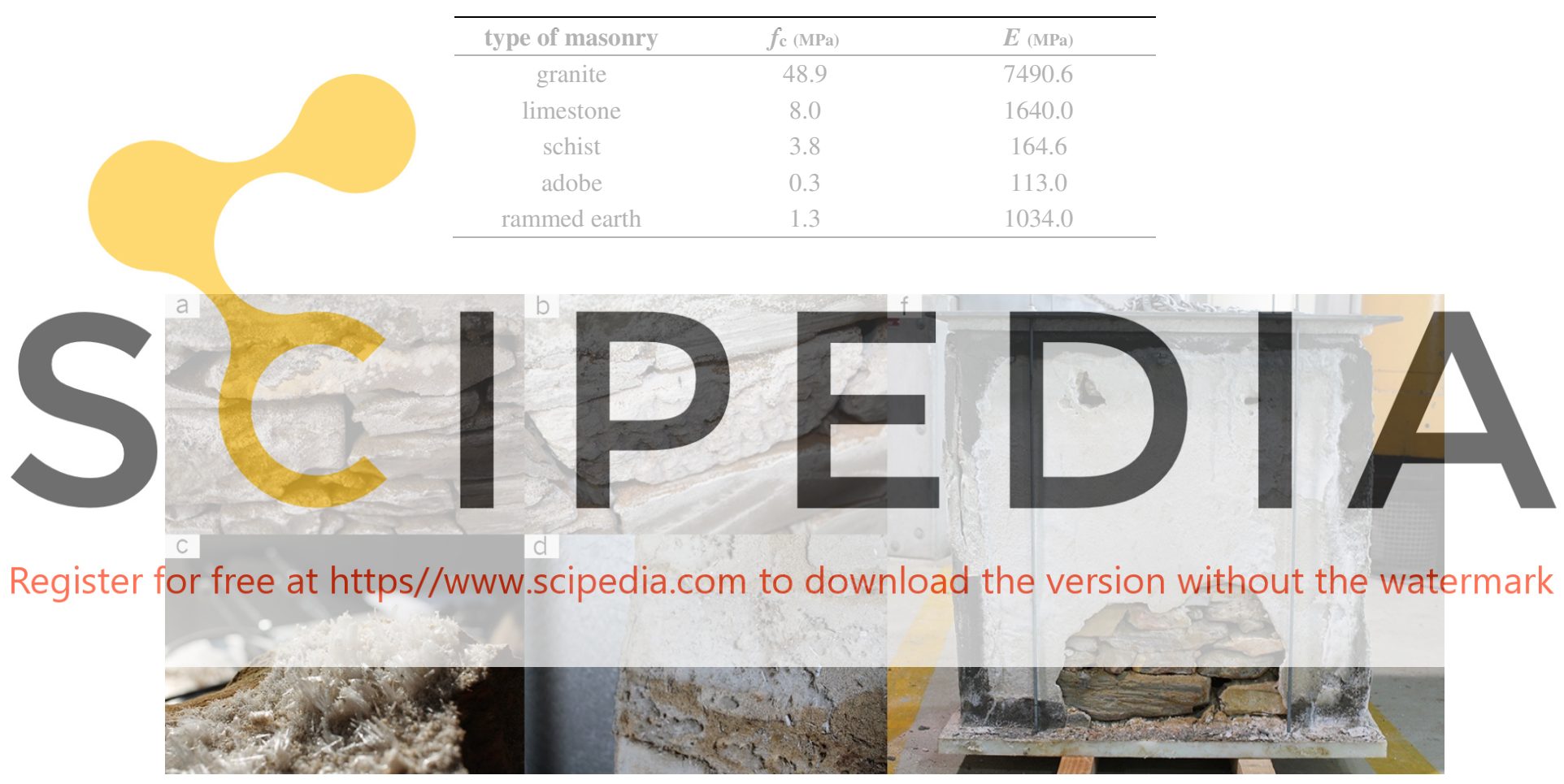

Figure 6: Damage observed during the WA test: (a) and (b) examples of different salt deposits on schist stone; (c) efflorescence; (d) efflorescence located at the coating/masonry interface; (f) example of WAC with superficial salt deposits, ruptured lime coating and detached lateral covers.

Damage in WAC main faces coatings was always severe in one side of the wallet (typically face A), with full coating thickness fractures and even ruptures. On the opposite side, only superficial crack patterns were detected, and were similar to the ones observed for the WAI wallets. On one hand, these results show that higher amounts of water inside wallets resulted in higher levels of damage on coatings. On the other, it became clear that water follows out through the easier way, in this case through the damaged coating, thus avoiding blockades and causing less damage over the remaining coatings. The observed preferential penetration 
direction (face A) seems to be related to unforeseen effects related to the solution for water circulation inside the tank.

Without coatings, such behaviour was not clear on WAN wallets, and was not observed in WAI wallets. A lower percentage of internal voids restricted water movements inside WAI wallets, and it seems the injection hose's tips provided a stronger stone/coating connection, preventing coating detachment or severe mechanical damage. By the end of the natural drying stage, due to salt accumulation at the interface, lateral covers detached from masonry in WAN and WAC wallets. In all WA wallets, salt accumulation at the interface between the coatings and the final waterproofing coating, caused the latter to rupture. By the end of WA test, control specimens showed lamellar rupture, and severe powdering faces and edges [17].

Analysing stress-strain diagrams in Figure 7, the similar brittle behaviour for all tested wallets and for both testing conditions is clear. $\mathrm{N}$ and $\mathrm{C}$ wallets showed a trilinear behaviour for all tested wallets, characterized by a very short initial linear stiff branch until the cracking of the first large stone block, followed by a longer deformation branch (non-linear) up to peak. As shown in the cyclic behaviour diagrams, $\mathrm{N}$ and $\mathrm{C}$ wallets linear hysteretic cycles reveal inability to dissipate energy, but almost no strength degradation was observed. Figure 7 shows stronger and stiffer I wallets when compared with the non-injected wallets.
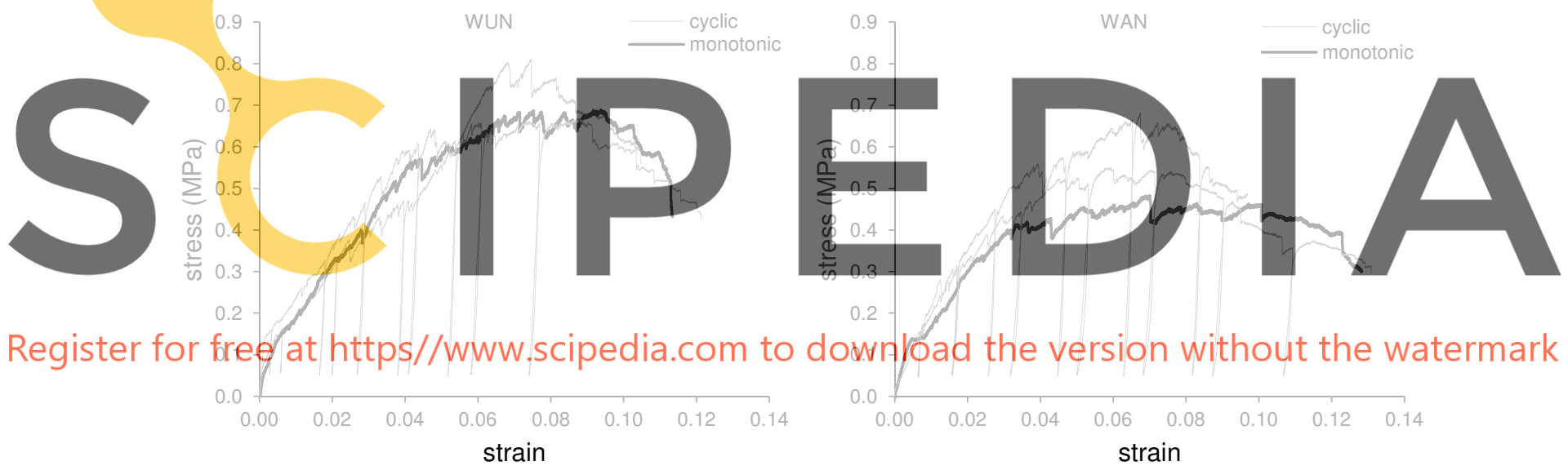

0.2
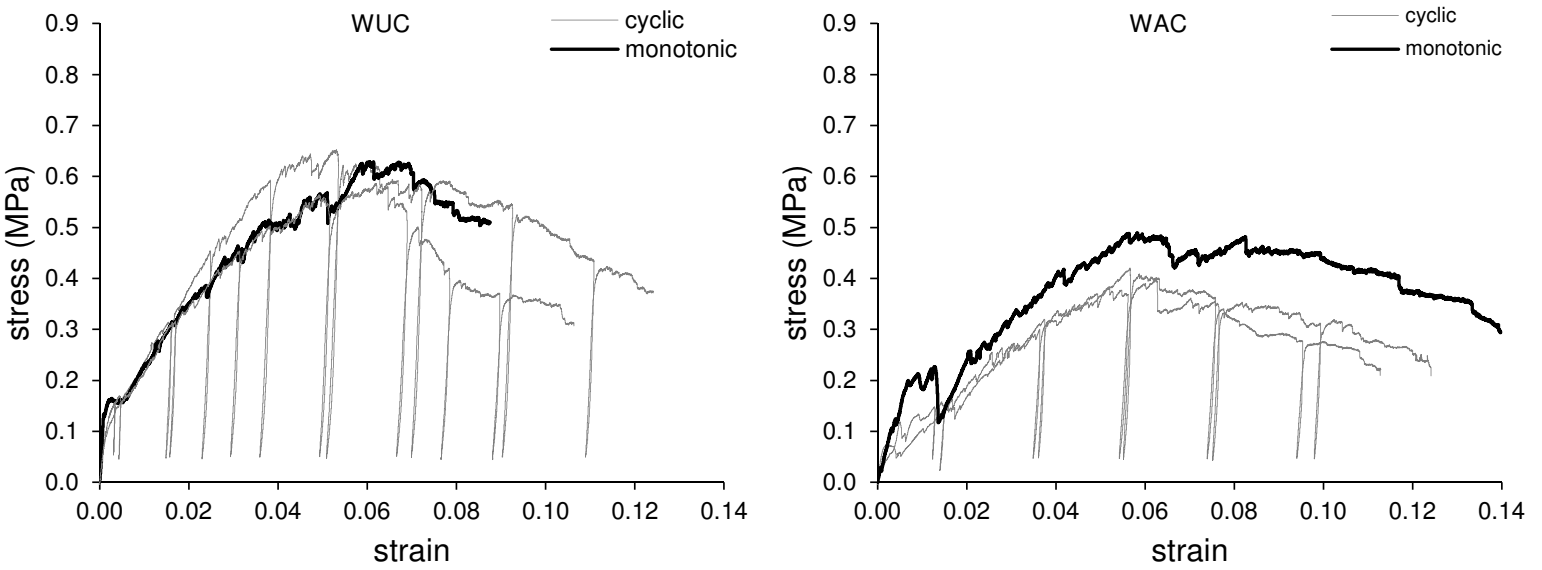

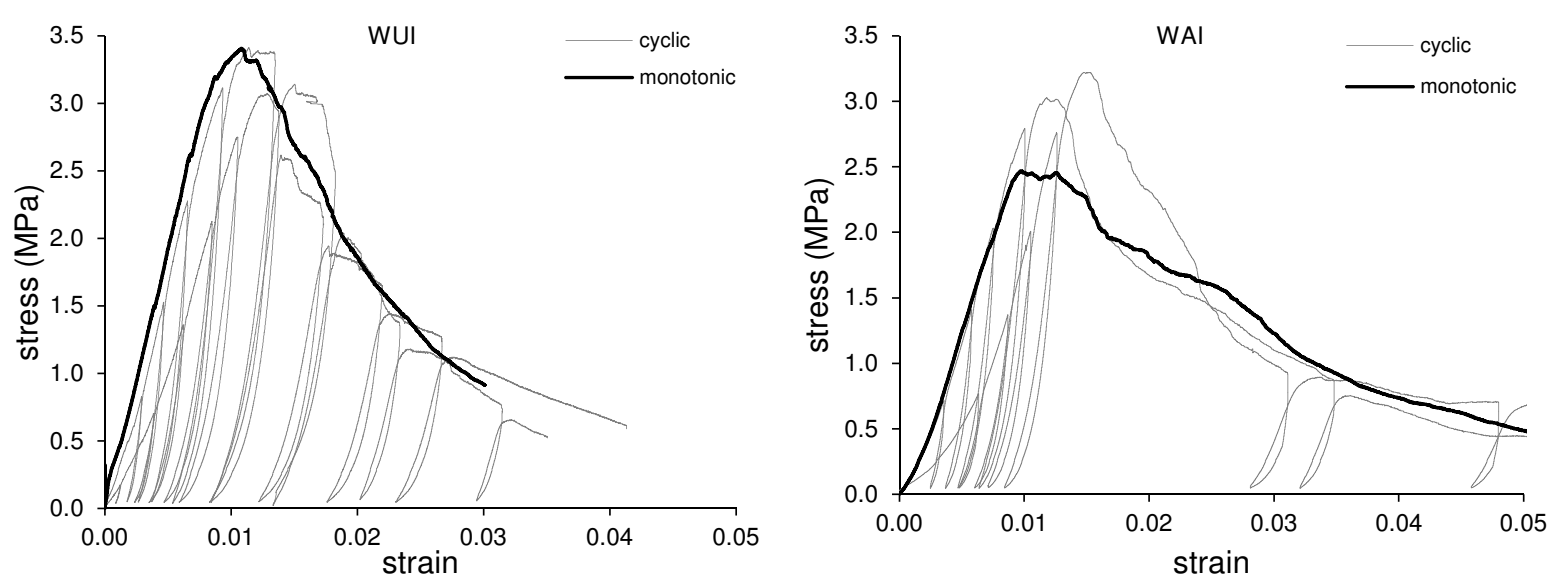

Figure 7: Stress-strain diagrams for WU (left) and WA (right) wallets.

The observed bilinear behaviour is characterized by a long stiff branch almost up to peak. The hysteretic curves confirm the injected masonry higher stiffness, with undeniable recovery capability in unloading-loading cycles. However, I wallets diagrams also show an initial accommodation stage that may be related to the use of soil as mortar.

Figure 8 and Figure 9 illustrate typical failure patterns, which may be described in 4 levels: (1) damage started with the expuision of mortar joints due to compression, with sight opening of joints and cracking of smaller stones and wedges; (2) the fracture of arger stone blocks, generally located at the lower half of the vallet, led to the formation of diagonal cracks, which propagate through joints, causing the detachment and rupture of the coating. (3) external ldaves start to deform and to detach, and large and deep cracks propagate witb large opened joints exposing the inner-core, (4) external leaves start to disintegrate by losing loose and ctushed stone blocks. Due to very poor bond in N and C masonry, wallets show higher deformability

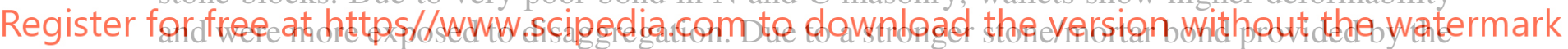
grout, I wallets disaggregate into large blocks of masonry.
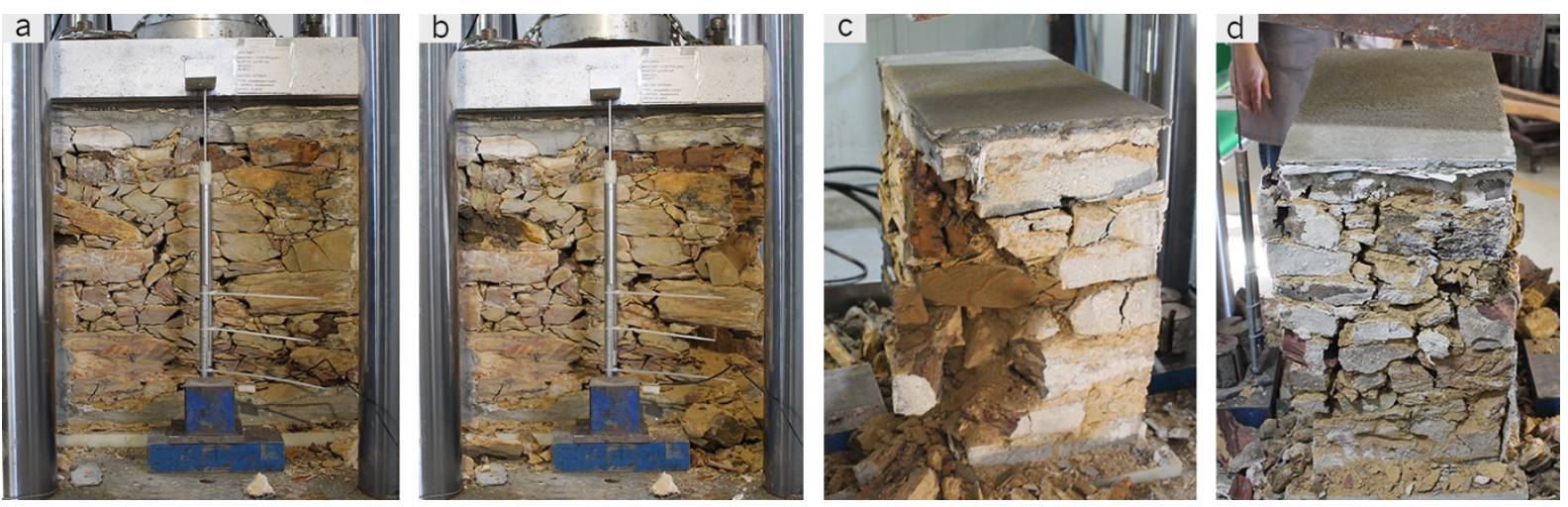

Figure 8: Example of WUN wallet: (a) initial damage with opening of joints and cracking of smaller stones and wedges; (b), (c) and (d) final damage with deep cracks, loss of stone blocks and leaves detachment. 

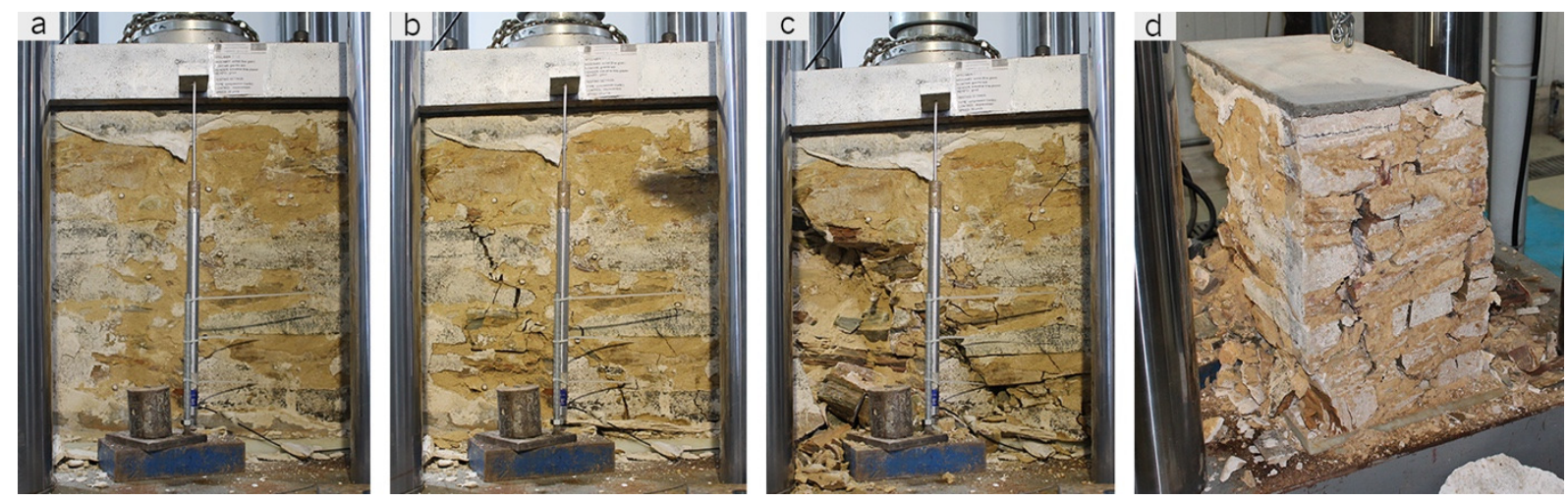

Figure 9: Example of tested WAI: (a) initial damage (visible after the rupture of the coating) with opening of joints and cracking of smaller stones and wedges; (b) formation of large diagonal cracks and fractures in stone

blocks; (c) and (d) extensive damage with disaggregation of leaves and formation of different blocks.

\section{CONCLUSIONS}

From the research presented in this paper, it became clear the low strength and stiffness of vernacular rubble schist masonry from Northwest Portugal. The use of lime coatings, similar to traditional ones, does not affect the masonry strength, but it seems to have a positive influence over stiffness.

Results show that grout injection increases is effective in filling the voids, thus it improves vernacular schist rubble masonry mechanical performance. Simultaneously, results show that this retrofitting technique reduces water penetration and accumulation inside walls, thus improving its durability.

Regarding failure, the cracking of larger stone blocks decisively affects rubble masonry stiffness. The opening of joints, the detachment of leaves and disaggregation of leaves, caused by deformation, were the most common types of mechanical damage.

The accelerated aging tests, with full immersion in salted water and drying cycles, to cause aging, as proven its validity to analyse stone masonry durability.

Without the grout protection, aged schist masonry presented severe damage and mechanical performance losses due to the washing and settlement of mortars. Damage also resulted from the cracking and rupture of coatings, due to salt damage at the coating/masonry interface. Although the overwhelming salt damage observed in the surfaces of the stone blocks posed no immediate structural threat, preliminary tests revealed that it inevitably evolves to the complete disintegration of stone blocks (lamellar and granular).

Acknowledgements. This work was partially financed by FEDER funds through the Competitivity Factors Operational Programme (COMPETE) and by national funds through the Foundation for Science and Technology (FCT) within the scope of project POCI-01-0145FEDER-007633. Authors wish to express their gratitude to S. Pedro de Rates Civil Parish for its support with the wallets' preparation. The first author expresses his gratitude to the Portuguese Science and Technology Foundation for the scholarships granted (SFRH/BD/ 86704/2012). 


\section{REFERENCES}

[1] D. V. Oliveira, R.A. Silva, E. Garbin, P.B. Lourenço, Strengthening of three-leaf stone masonry walls: an experimental research, Mater. Struct. 45 (2012) 1259-1276.

[2] C.E. Barroso, D. V. Oliveira, L.F. Ramos, Vernacular schist farm walls: materials, construction techniques and sustainable rebuilding solutions, J. Build. Eng. 15 (2018).

[3] T. Wijffels, B. Lubelli, Development of a new accelerated salt crystallization test, Heron. 51 (2006) 63-75.

[4] H. Van Eldere, F. Ramos, E. Verstrynge, N. Shetty, K. Van Balen, C.E. Barroso, The Application of Sonic Testing on Double-LEaf Historical Portuguese Madonry to Obtains Morphology and Mechanical Properties, in: R. Aguilar, D. Torrealva, S. Moreira, M.A. Pando, L.F. Ramos (Eds.), Struct. Anal. Hist. Constr. (RILEM Bookseries), 1st ed., Springer International Publishing, 2019.

[5] C.E. Barroso, D. V. Oliveira, L.F. Ramos, Preservation of vernacular schist masonry farm walls, in: C. Mileto, F. Vegas, J.G. Soriano, V. Cristini (Eds.), VERSUS2014 - Vernac. Archit. - Towar. a Sustain. Futur., CRC Press/Balkema, Valencia, 2015: pp. 117-122.

[6] ICOMOS, Charter on the built Vernacular Heritage (1999), Mexico, 1999.

[7] ICOMOS-IFLA, ICOMOS-IFLA principles concerning rural landscape as heritage, New Delhi, 2017.

[8] ICOMOS, The Nara document on autenticity, Nara, 1994.

[9] C.E. Barroso, The rural vernacular construction of the Entre-Douro-e-Minho, $\mathrm{PhD}$ Thesis, University of Minho, 2018.

[10] BS EN 1052-1:1999, Methods of test for masonry - Part 1: Determination of compressive strength, (1999).

[11] C. Rodriguez-Navarro, E. Doehne, Salt weathering: influence of evaporation rate, supersaturation and crystallization pattern, Earth Surf. Process. Landforms. 24 (1999).

[12] A. Goudie, H. Viles, Salt Weathering Hazards, John Wiley \& Sons, Oxford, 1997.

[13] NP EN 12370, Natural stone test methods - Determination of resistance to salt crystallisation (in Portuguese), (2001).

[14] A.E. Charola, Salts in the Deterioration of Porous Materials : An Overview., J. Am. Inst. Conserv. 39:3 (2000) 327-343.

[15] E.C.P. Luso, Experimental analysis of lime-based grouts for the injection of ancient masonry (in Portuguese), PhD Thesis, University of Minho, 2012.

[16] R.S. Barros, Material and structural behaviour assessment of buildings in schist (in Portuguese), PhD Thesis, University of Minho, 2013.

[17] V. Verges-Belmin, Illustrated glossary on stone deterioration patterns, 2008.

[18] I. Jiménez-González, C. Rodríguez-Navarro, G.W. Scherer, Role of clay minerals in the physicomechanical deterioration of sandstone, J. Geophys. Res. 113 (2008). 